October 2017, Volume 1, Issue 4

\title{
Breast Cancer Coping Strategies after Diagnosis: A Six-month Follow-up
}

Akram Sajadian ${ }^{1,}{ }^{*}$, RajiLahiji Mahsa ${ }^{1}$, Akram Motaharinasab ${ }^{1}$, Anoshirvan Kazemnejad ${ }^{2}$, Shahpar Haghighat ${ }^{1}$

${ }^{1}$ Quality of life Department, Breast Cancer Research Center, Motamed Cancer Institute, ACECR, Tehran, Iran

${ }^{2}$ Department of Biostatistics, Faculty of Medical Sciences, Tarbiat Modares University, Tehran, Iran

* Corresponding author: Akram Sajadian, Quality of life Department, Breast Cancer Research Center, Motamed Cancer Institute, ACECR, Tehran, Iran.E-mail: assajadi@

DOI: $10.21859 / \mathrm{mci}-01042$ yahoo.com
Submitted: 1 September 2017

Revised: 21 September 2017

Accepted: 25 September 2017

ePublished: 1 October 2017

\section{Keywords:}

Spirituality

Breast Neoplasms

Iran

\begin{abstract}
Introduction: Breast cancer is a tragic experience that accompanies stressful situations for patients. Adjustment with breast cancer has a significant effect on decreasing stress and increasing the patients > quality of life.

Methods: In a prospective cross-sectional study, breast cancer patients $>$ experiences were evaluated at Breast Cancer Research Center (BCRC), Motamed Cancer Institut (MCI), Tehran, Iran. To evaluate coping strategies in breast cancer patients, a modified Ways of Coping-cancer Version (WOC-CA) questionnaire was used. A written informed consent was obtained from the patients.

Results: From a total of 187 breast cancer patients participated in this study, 177 cases followed up for 6 months later. The mean age of the patients was $47.3 \pm 9.6$ years. Eighty-seven percent of the patients were married, $91 \%$ of the subjects had middle and high education and most of them $(83 \%)$ were housewife. Seven coping strategies were used by the patients after diagnosis and 6 months later. The most commonly used coping strategies after diagnosis included «seeking for social support», «spirituality», and «positive cognitive restructuring» and the least used coping strategy was «detachment». The most frequently used strategies 6 months after the diagnosis were «seeking for social support», «spirituality», «positive cognitive restructuring», and «making changes $\gg$ and the least commonly used ones included « wishful thinking», and «keeping feelings to self-coping strategies».

Conclusions: It seems that clinicians should provide enough information about the treatment and survival before the surgery. The patients> concerns about the way of adjustment with the disease, especially religious thinking and advices about the way of coping with breast cancer should be considered.
\end{abstract}

(C) 2017. Multidisciplinary Cancer Investigation

\section{INTRODUCTION}

Among all types of cancers, breast cancer is the most common cancer among women in all over the world [1]. According to the latest report by the Cancer Control Office in Iran, breast cancer age-specific incidence rates per10,000 population [2]. The highest rate of breast cancer is in the United States of America, Australia, New Zealand, South America, Eastern and Western Europe, and the incidence is rising rapidly in many developing countries [3]. According to the data from 2009 to 2013 in the United States, the number of new cases of female breast cancer was 125 per 100,000 women per year [4]. Psychosocial distress has been identified as an important issue for patients with cancer. In fact, it is estimated that one-third of patients with cancer will experience signif- icant emotional and psychological distress during their cancer experience [5]; about $30 \%$ of them had degrees of anxiety and depression during the first year of their diagnosis, which is 3-4 times more than the general population [6]. The breast cancer illness trajectory has several challenges for women: adjusting to bad news; decision making for treatment; worry about the side-effects of treatment; thinking about disease-free survival or recurrence; and finally acceptance of death. The loss part of one or both breasts may evoke feelings of mutilation and altered body image, diminished self-worth, loss of a sense of femininity, decrease in sexual attractiveness and function, anxiety, depression, hopelessness, guilt, shame, and fear of recurrence, abandonment and/or death. The 
removal of a breast should be understood as an amputation of a body part, a part that symbolizes sexuality, femininity, gender and maternal issues [3]. Through the breast cancer diagnosis most patients have fear with negative emotions. In addition, stress and some difficulties about the cancer stigma products may lead the patients to use different types of coping strategies. Lazarus and Folkman define coping as a dynamic process involving cognitive and behavioral efforts to enable people to live with internal or external demands brought about by disease [7]. Previous cross sectional findings [8-12] suggest that women with breast cancer who use strategies such as positive cognitive restructuring (also known as positive reappraisal), acceptance, emotional processing, or emotional expression have better quality of life than those who use more passive coping strategies such as avoidance or minimizing importance of their cancer.

The meta-analysis in 2014 [13] indicated that in several circumstances, coping effectiveness was dependent on cancer stage, treatment, disease duration, and type of coping measure. Use of coping targeting adjustment and avoiding use of disengagement forms of coping were related to better psychological well-being and physical health. A longitudinal study that followed women for up to 5 years found that variability in coping strategies was observed at times of greatest stress (treatment, recurrence, and terminal phase of cancer) and suggested that change in coping strategies may be linked more to "illness stages" than to any specific length of time since diagnosis [14]. The use of coping strategies was associated with adjustment with the disease and increasing quality of life of the patients after breast cancer diagnosis [15-18]. The role of religion and spirituality in coping with illness has received relatively little attention as a specific area of study. By and large, studies examining religious coping in medically ill patients have found that between $34 \%$ and $86 \%$ have reported using their religious/spiritual cognitions and activities in coping with their illness $[19,20]$. In Iran, several qualitative studies have been conducted on the experiences of patients with breast cancer. In general, these studies have highlighted that the most important coping methods are religious beliefs, thinking and acceptance of the illness $[3,21]$. At different stages, women need different interventions. For example, those who are newly diagnosed with cancer may benefit more from interventions that last about 6 to 10 weeks. In addition, patients with more survival can benefit more from monthly and patient-centered interventions [22-24]. Therefore, it seems necessary to have coping behaviors presented in order to provide patient with qualified medical assistance. In psycho-oncological research, these investigations have helped shift the focus from patients' dispositional religiousness to their specific responses to illness. However, only few items or a single scale were used and predominantly positive aspects of religious coping were measured [25]. This study aimed to examine coping strategies among women with breast cancer at first diagnosis and 6 months after the diagnosis (treatment) and to explore the potential moderating influences of situational factors (cancer stage, current treatments, time since diagnosis) on the disease.

\section{METHODS}

This longitudinal study was conducted on 187 patients with cancer at the Cancer Quality of Life Department, Breast Cancer Research Center, Motamed Cancer Institute (ACECR), Tehran, Iran. In this study, the patients with breast cancer were interviewed by trained interviewers at baseline via a structured questionnaire. Then, approximately 6 months after the initial diagnosis of the breast cancer, 177 cases completed the follow-up questionnaire. The follow-up interview was conducted using a coping questionnaire, which assessed information similar to that obtained at baseline. The structured questionnaire was designed according to the previous studies' questionnaires that determined coping strategies in breast cancer patients [26-29]. The content validity was confirmed using two methods (qualitative and quantitative). In the qualitative phase, an expert panel consisting of two psychiatrist experts, six health science professionals, one epidemiologist expert and an expert on social medicine assessed the content validity. Experts evaluated grammar, wording, item allocation and scaling of the questionnaire. In the quantitative phase, two indicators were calculated: the content validity index (CVI) and the content validity ratio (CVR). Internal consistency reliability was 0.79 as measured by Cronbach's alpha 0.75 .

This questionnaire consists of 21 items making up the seven factors: "seeking and using social support", "keeping feelings to self", "positive cognitive restructuring", "wishful thinking", "making changes", "spirituality", and "detachment". In this study, breast cancer patients were asked about which coping strategies they used to cope with their situation. At baseline, they were asked to respond for the time since their breast cancer diagnosis; at both follow-up time points, they were asked to respond for the past 6 months. The response format was based on a 5-point Likert scale where $1=$ not at all, $2=$ rarely, $3=$ sometimes, $4=$ often, and $5=$ very often.

The data collected from the patients were analyzed using descriptive and analytical statistics by the SPSS version 20. To compare different coping strategies, the mean scores of the factors were compared. We examined the relationship between demographic factors and coping strategies, using the chi-square test and $\mathrm{P}$ value $<0.05$ was significant. Then, coping strategies were compared using paired-samples t-test and one-way ANOVA.

\section{RESULTS}

A total of 177 participants were completed questionnaires in two steps after breast cancer diagnosis and 6 months after diagnosis. 
Participant's socio-demographic characteristics, disease, tumor, and treatment characteristics are presented in table 1 . The women's age ranged from 26 to 83 years with a mean of $47.32 \pm 9.6$ years. Eighty-seven percent of the subjects were married, $83 \%$ were housewife and $91 \%$ were educated. Results showed that 48 women were in stage I, 87 patients were in stage II, and 52 cases were in stage III of the breast cancer diagnosis. Also, mastectomy had been performed in $82 \%$ of the subjects and 101 women had a breast-conserving surgery (Table 1).

Patients used several coping strategies. There was a significant difference in the mean scores of coping strategies after the diagnosis and 6 months later $(46.37 \pm 11.42$, and $51.48 \pm 9.80$, respectively; $\mathrm{P}<0.0001$ ) (Table 2 ).

The mean scores of the most commonly used coping strategies including seeking social support, spirituality and positive cognitive restructuring immediately after diagnosis were $57.4 \pm 20,83.3 \pm 23$, and $59 \pm 23$, respectively. .While detachment was the least commonly used coping strategy with the mean score of $45 \pm 26$. The mean scores of the most frequently used strategies including seeking for social support, spirituality, positive cognitive restructuring, and making changes 6 months after the diagnosis were $65 \pm 18,87.5 \pm 18,70.5 \pm 21$, and $64.4 \pm 23$, respectively. While the least commonly used strategies were wishful thinking and keeping feelings to self-coping strategies with the mean scores of 27.6 \pm 25 and $45 \pm 23$, respectively. Results after a 6-month follow-up showed that strategies such as spirituality ( $\mathrm{P}$ $<0.04$ ), seeking social support, positive cognitive restructuring, detachment and making changes were used significantly more than at the time of diagnosis $(\mathrm{P}<$ 0.0001 ) and the coping strategy of keeping feeling was used less than at the time of diagnosis $(P<0.003)$. The spirituality was the most common coping strategy used after the diagnosis and 6 months later $(\mathrm{T}=83.33$, and $\mathrm{T}$ $=87.57$, respectively $)(\mathrm{P}<0.04)$. The results of the present study showed no significant difference between the coping strategies and demographic factors. The participants were asked open-ended questions and the results showed that women with further stress used coping strategies most frequently.

\section{DISCUSSION}

The aim of this longitudinal study was to examine coping strategies among women with breast cancer before and after treatment. In this study we found that the most commonly used coping strategies immediately after diagnosis and 6 month later were seeking social support, spirituality and positive cognitive restructuring, only the making changes coping strategies after treatment was greater. Detachment was the least commonly used coping strategy after diagnosis. While the least commonly used coping strategies 6 months after diagnosis were wishful thinking and keep feelings. Our results indicated that patients after breast cancer diagnosis used several coping strategies in agreement with the Lazarus and Folkman's model [29], which showed that breast cancer patients used various coping strategies after diagnosis in response to stress. Previous studies have demonstrated that some common coping strategies used by

\begin{tabular}{lc} 
Table 1: Demographic Characteristics $(\mathrm{n}=177)$ & \\
\hline Baseline Characteristics & No. $(\%)$ \\
\hline Occupation & $156(83)$ \\
\hline House wife & $31(17)$ \\
\hline Employee & \\
Education & $16(9)$ \\
\hline Illiterate & $77(41)$ \\
\hline High school & $63(34)$ \\
\hline Diploma & $31(16)$ \\
\hline Collegiate & \\
\hline Marital status & $25(13)$ \\
Single & $162(87)$ \\
\hline Married & \\
\hline Stage & $26(48)$ \\
I & $46(87)$ \\
\hline II & $52(28)$ \\
\hline III & \\
\hline Type of surgery & $82(45)$ \\
\hline Mastectomy & $101(55)$ \\
\hline Conserving surgery & \\
\hline & \\
\hline
\end{tabular}

Table 2: Comparison of Coping Strategies before and after the Treatment

\begin{tabular}{lccc}
\hline & Before treatment & After treatment & P value \\
\hline Total coping & Mean(SD) & Mean(SD) & 0.0001 \\
Seeking/Social support & $46.37(11)$ & $51.48(9)$ & 0.0001 \\
Keeping feeling & $57.40(20)$ & $65.08(18)$ & 0.003 \\
Positive cognitive reconstraction & $54.38(26)$ & $47.10(23)$ & 0.0001 \\
Spirituality & $59.09(23)$ & $70.48(21)$ & 0.041 \\
Detachment & $83.33(53)$ & $87.57(18)$ & 0.0001 \\
Making changes & $45.13(20 / 53)$ & $58.65(22 / 94)$ & 0.0001 \\
\hline Wishful thinking & $48.25(26)$ & $64.39(23)$ & 0.0001 \\
\hline
\end{tabular}


breast cancer patients were positive cognitive restructuring, wishful thinking, emotional expression, disease acceptance, increased religious practice, family and seeking social support [29-31] Our results seem to be consistent with those of other studies, which found coping strategies changed over time $[24,31,32]$. Another important finding was that wishful thinking was the least commonly used strategy 6 months after the diagnosis. These results are in agreement with those observed in earlier studies [8]. While, a recent study showed that wish and avoidance thinking was mostly used $(69.0 \%)$ in Gaza patients with cancer to deal with stressful situations [33]. The most important aspects of coping with breast cancer in Iranian women at both steps were spiritual coping strategy. In religious communities, it seems that the coping strategy of spirituality may help decrease stress in cancer patients and facilitate social support. Thus, health care providers who work with women diagnosed with breast cancer in these communities should be aware of the culturally dependent roles that religion and spirituality play in coping with cancer [30]. Some of patients believed in their disease as a spiritual fate, a test bestowed on them by God. As they believed all power rested with God, they surrendered themselves to their fate [34]. Religious faith and practice were the most frequent coping responses among women with cancer who "trusted God" about the course of their illness became stronger believers in an after-life concept and were less afraid of death [35]. Other studies were showed that spirituality was not separate from religion $[30,35]$. Spiritual coping strategy is defined as a process that people utilize to find meaning in stressful circumstances [35] and relieve it. Six months after diagnosis the Keep feelings strategy was less used than other strategies for coping with cancer. These results are consistent with other studies that showed keeping feelings to oneself was the least used coping strategy and its use remained consistently low over time. On the contrary, the coping strategy of wishful thinking at first time was used more than the second time. These findings seem to be consistent with those of other researches $[8,31]$. These results were also supported findings from studies that the seeking social support, positive cognitive restructuring, making changes and detachment were main coping strategies, which had been used more than other strategies after diagnosis and 6 months later. Some of the studies classified social support as 'a problem-focused coping strategy', or 'emotion-focused coping strategy [5, 31, 36-38]. However, seeking social support is one of the main coping strategies used after diagnosis for information seeking and 6 months later for family and social support.

Positive cognitive restructuring is one of the most commonly used coping strategies in breast cancer patients after as a fighter in the battle for win. But after 6 months they used this strategy as a lifetime adaptive strategy. However, if persons employed positive reappraisal in one encounter, they were also likely to employ it in other encounters [29]. Chen and et al. demonstrated that acceptance is one of the most common types of coping reactions and it can prospectively predict lower distress. Most of the participants progressed from one stage of acceptance to the next as the treatment stage changed [39]. The making changes coping strategy after spirituality and positive cognitive restructuring were used more than other coping strategies after 6 months. In some patients, using the coping strategy of making changes is impossible after breast cancer diagnosis, but 6 months later they can easily use this strategy. Other studies have shown similar results $[31,40]$.

To examine whether the demographic factors might have influenced coping, we compared mean coping scores for each coping strategy after diagnosis and 6 months later. No significant association was found between the coping strategies and demographic characteristics. This study had several limitations. First, the studied participants were middle educated women. Second, we fulfill this study in a special breast clinic and we had naturally limited access to patients. The major strength of this study was the use of follow-up data to examine relationships between coping strategies. We know that this finding is suggestive and not definitive. Examining the relationship between coping strategies after 6 months or more is difficult and this is an important issue for future research.

\section{ACKNOWLEDGEMENTS}

The current study did not receive any financial support.

\section{CONFLICT OF INTEREST}

The authors declared that they have no conflict of interest.

\section{ETHICS APPROVAL}

This study approved by the ethics committee of the Breast Cancer Research Center of ACECR with the code IR.ACECR.IBCRC.REC.1395.15.

\section{REFERENCES}

1. Bray F, Ren JS, Masuyer E, Ferlay J. Global estimates of cancer prevalence for 27 sites in the adult population in 2008 . Int J Cancer. 2013;132(5):1133-45. DOI: 10.1002/ijc.27711 PMID: 22752881

2. Naghavi M. Iranian annual of national death registration report. Tehran: Ministry of Health and Medical Education, 2012.

3. Taleghani F, Parsa Yekta Z, Nikbakht Nasrabadi A. 3Coping with breast cancer in newly diagnosed Iranian women. J Adv Nurs. 2006;54(3):265-72.

4. SEER. SEER Stat Fact Sheets: Female Breast Cancer 2013 [cited 20164 June]. Available from: http://seer.cancer.gov/ statfacts/html/breast.html.

5. Nekolaichuk CL, Cumming C, Turner J, Yushchyshyn A, Sela R. Referral patterns and psychosocial distress in cancer patients accessing a psycho-oncology counseling service. Psy- 
chooncology. 2011;20(3):326-32. DOI: 10.1002/pon.1765 PMID: 20878858

6. Montazeri A, Harirchi I, Vahdani M, Khaleghi F, Jarvandi S, Ebrahimi M, et al. Anxiety and depression in Iranian breast cancer patients before and after diagnosis. European Journal of Cancer Care. 2000;9(3):151-7. DOI: DOI 10.1046/j.13652354.2000.00219.x PMID: WOS:000090132000020

7. Lazarus R, Folkman S. Stress appraisal and coping. New York: Springer ed; 1984

8. Danhauer SC, Crawford SL, Farmer DF, Avis NE. 19A longitudinal investigation of coping strategies and quality of life among younger women with breast cancer. J Behav Med. 2009;32(4):371-9.

9. Avis NE, Crawford S, Manuel J. Quality of life among younger women with breast cancer. J Clin Oncol. 2005;23(15):332230. DOI: $10.1200 / \mathrm{JCO} .2005 .05 .130$ PMID: 15908646

10. Folkman S. Stress: appraisal and coping. Encyclopedia of behavioral medicine: Springer; 2013. p. 1913-5.

11. Sehlen S, Song R, Fahmuller H, Herschbach P, Lenk M, Hollenhorst $\mathrm{H}$, et al. Coping of cancer patients during and after radiotherapy--a follow-up of 2 years. Onkologie. 2003;26(6):557-63. DOI: 74151 PMID: 14709930

12. Stanton AL, Danoff-Burg S, Cameron CL, Bishop M, Collins CA, Kirk SB, et al. Emotionally expressive coping predicts psychological and physical adjustment to breast cancer. J Consult Clin Psychol. 2000;68(5):875-82. PMID: 11068973

13. Kvillemo P, Branstrom R. Coping with breast cancer: a meta-analysis. PLoS One. 2014;9(11):e112733. DOI: 10.1371/ journal.pone.0112733 PMID: 25423095

14. Heim E, Valach L, Schaffner L. Coping and psychosocial adaptation: longitudinal effects over time and stages in breast cancer. Psychosom Med. 1997;59(4):408-18. PMID: 9251161

15. Dukes Holland K, Holahan CK. The relation of social support and coping to positive adaptation to breast cancer. Psychol Health. 2003;18(1):15-29.

16. Epping-Jordan JE, Compas BE, Osowiecki DM, Oppedisano G, Gerhardt C, Primo K, et al. Psychological adjustment in breast cancer: processes of emotional distress. Health Psychol. 1999;18(4):315-26. PMID: 10431932

17. Hack TF, Degner LF. Coping responses following breast cancer diagnosis predict psychological adjustment three years later. Psychooncology. 2004;13(4):235-47. DOI: 10.1002/ pon.739 PMID: 15054728

18. Kershaw T, Northouse L, Kritpracha C, Schafenacker A, Mood D. Coping strategies and quality of life in women with advanced breast cancer and their family caregivers. Psychol Health. 2004;19(2):139-55. DOI: $10.1080 / 08870440310001652687$

19. Koenig HG. Religious attitudes and practices of hospitalized medically ill older adults. Int J Geriatr Psychiatry. 1998;13(4):213-24. PMID: 9646148

20. Ayele H, Mulligan T, Gheorghiu S, Reyes-Ortiz C. Religious activity improves life satisfaction for some physicians and older patients. J Am Geriatr Soc. 1999;47(4):453-5. PMID: 10203121

21. Harandy TF, Ghofranipour F, Montazeri A, Anoosheh M, Bazargan M, Mohammadi E, et al. 11Muslim breast cancer survivor spirituality: coping strategy or health seeking behavior hindrance? Health care for women international. 2009;31(1):88-98.

22. Farajzadegan Z, Khalili N, Mokarian F. Coping Skill Improve Quality of Life in Women with Breast Cancer and Maladaptive Coping Style. Psycho-Oncology. 2015;24(1):212-3.

23. Mitchell SA, Beck SL, Hood LE, Moore K, Tanner ER. Putting evidence into practice: evidence-based interventions for fatigue during and following cancer and its treatment. Clin J Oncol Nurs. 2007;11(1):99-113. DOI: 10.1188/07.
CJON.99-113 PMID: 17441401

24. McCaul KD, Sandgren AK, King B, O’Donnell S, Branstetter A, Foreman G. Coping and adjustment to breast cancer. Psychooncology. 1999;8(3):230-6. DOI: 10.1002/(SICI) 1099 1611(199905/06) 8:3<230::AID-PON374>3.0.CO;2-\# PMID: 10390735

25. Thune-Boyle IC, Stygall JA, Keshtgar MR, Newman SP. Do religious/spiritual coping strategies affect illness adjustment in patients with cancer? A systematic review of the literature. Soc Sci Med. 2006;63(1):151-64. DOI: 10.1016/i socscimed.2005.11.055 PMID: 16427173

26. Sajadian A, Montazeri A. Survivor's point of view after breast cancer. Eur J Cancer Supplem. 2010;8(3):85-. DOI: Do 10.1016/S1359-6349(10)70124-5

27. Montazeri A, Vahdaninia M, Ebrahimi M, Jarvandi S. The Hospital Anxiety and Depression Scale (HADS): translation and validation study of the Iranian version. Health Qual Life Outcomes. 2003;1(1):14. DOI: 10.1186/1477-7525-1-14 PMID: 12816545

28. Hjorleifsdottir E, Hallberg IR, Bolmsjo IA, Gunnarsdottir ED. Distress and coping in cancer patients: feasibility of the Icelandic version of BSI 18 and the WOC-CA questionnaires. Eur J Cancer Care (Engl). 2006;15(1):80-9. DOI: 10.1111/j.1365-2354.2005.00620.x PMID: 16441681

29. Lazarus RS. Coping theory and research: past, present, and future. Psychosom Med. 1993;55(3):234-47. PMID: 8346332

30. Al-Azri M, Al-Awisi H, Al-Moundhri M. 10Coping With a Diagnosis of Breast Cancer-Literature Review and Implications for Developing Countries. The Breast Journal. 2009;15(6):615-22.

31. Manuel JC, Burwell SR, Crawford SL, Lawrence RH, Farm er DF, Hege A, et al. Younger women's perceptions of coping with breast cancer. Cancer Nurs. 2007;30(2):85-94. DOI 10.1097/01.NCC.0000265001.72064.dd PMID: 17413773

32. Drageset S, Lindstrom TC. Coping with a possible breast cancer diagnosis: demographic factors and social support. J Adv Nurs. 2005;51(3):217-26. DOI: 10.1111/j.13652648.2005.03495.x PMID: 16033589

33. Al Jadili M, Thabet A. The relationship between post-traumatic stress disorder and coping strategies among patients with cancer in Gaza Strip. J Nurs Health Stud. 2017;2:1

34. Taleghani F, Yekta ZP, Nasrabadi AN, Kappeli S. Adjustment process in Iranian women with breast cancer Cancer Nurs. 2008;31(3):E32-41. DOI: 10.1097/01. NCC.0000305720.98518.35 PMID: 18453870

35. Ahmad F, Muhammad M, Abdullah AA. Religion and spirituality in coping with advanced breast cancer: perspectives from Malaysian Muslim women. J Relig Health. 2011;50(1):36-45. DOI: 10.1007/s10943-010-9401-4 PMID: 20924683

36. Koopman C, Angell K, Turner-Cobb JM, Kreshka MA, Donnelly P, McCoy R, et al. Distress, coping, and social support among rural women recently diagnosed with primary breast cancer. Breast J. 2001;7(1):25-33. PMID: 11348412

37. Boehmke MM, Dickerson SS. The diagnosis of breast cancer: transition from health to illness. Oncol Nurs Forum 2006;33(6):1121-7. DOI: 10.1188/06.ONF.1121-1127 PMID: 17149395

38. Tan M. Social support and coping in Turkish patients with cancer. Cancer Nurs. 2007;30(6):498-504.DOI: 10.1097/01. NCC.0000300158.60273.ba PMID: 18025923

39. Chen SQ Liu JE, Li Z, Su YL. The process of accepting breast cancer among Chinese women: A grounded theory study. Eur J Oncol Nurs. 2017;28:77-85. DOI: 10.1016/i. ejon.2017.03.005 PMID: 28478860

40. Zhang J, Gao W, Wang P, Wu ZH. Relationships among hope, coping style and social support for breast cancer patients. Chin Med J (Engl). 2010;123(17):2331-5. PMID: 21034544 